\title{
An outbreak of locally acquired Plasmodium vivax malaria among migrant workers in Oman
}

\author{
Bruno Simon ${ }^{1}$, Fatimata Sow ${ }^{1}$, Said K. Al Mukhaini ${ }^{2}$, Seif Al-Abri ${ }^{3}$, Osama A.M. Ali ${ }^{2}$, \\ Guillaume Bonnot ${ }^{1}$, Anne-Lise Bienvenu ${ }^{1,4}$, Eskild Petersen ${ }^{5,6}$, and Stéphane Picot ${ }^{1,7, *}$ \\ 1 Malaria Research Unit, SMITh, ICBMS UMR 5246, University of Lyon, Campus Lyon-Tech La Doua, \\ 43 Boulevard du 11 Novembre 1918, 69622 Villeurbanne, France \\ 2 The Department of Malaria, Directorate General for Disease Surveillance and Control, Ministry of Health, \\ P. O. Box 393, Postal Code 113, Muscat, Oman \\ 3 Directorate General for Disease Surveillance and Control, Ministry of Health, P. O. Box 2657, CPO 111, Muscat, Oman \\ 4 Service Pharmacie, Hospices Civils de Lyon, 103 Grande Rue de la Croix-Rousse, 69317 Lyon, France \\ 5 Department of Infectious Diseases, The Royal Hospital, P. O. Box 1331, CPO 111, Muscat, Oman \\ ${ }^{6}$ Institute of Clinical Medicine, Faculty of Health Sciences, University of Aarhus, Palle Juul-Jensens Boulevard 82, \\ 8200 Aarhus N, Denmark
}

7 Institut de Parasitologie et Mycologie Médicale, Hospices Civils de Lyon, 103 Grande Rue de la Croix-Rousse, 69317 Lyon, France

Received 16 March 2017, Accepted 24 June 2017, Published online 11 July 2017

\begin{abstract}
Plasmodium vivax is the most widely distributed human malaria parasite. Outside sub-Saharan Africa, the proportion of $P$. vivax malaria is rising. A major cause for concern is the re-emergence of Plasmodium vivax in malaria-free areas. Oman, situated in the south-eastern corner of the Arabian Peninsula, has long been an area of vivax malaria transmission but no locally acquired cases were reported in 2004. However, local transmission has been registered in small outbreaks since 2007. In this study, a local outbreak of 54 cases over 50 days in 2014 was analyzed retrospectively and stained blood slides have been obtained for parasite identification and genotyping. The aim of this study was to identify the geographical origin of these cases, in an attempt to differentiate between imported cases and local transmission. Using circumsporozoite protein (csp), merozoite surface protein 1 ( $m s p l)$, and merozoite surface protein 3 ( $m s p 3$ ) markers for genotyping of parasite DNA obtained by scrapping off the surface of smears, genetic diversity and phylogenetic analysis were performed. The study found that the samples had very low genetic diversity, a temperate genotype, and a high genetic distance, with most of the reference strains coming from endemic countries. We conclude that a small outbreak of imported malaria is not associated with re-emergence of malaria transmission in Oman, as no new cases have been seen since the outbreak ended.
\end{abstract}

Key words: Malaria, Plasmodium vivax, Outbreak, Oman, Genotyping, Temperate genotype.

Résumé - Une épidémie de paludisme à Plasmodium vivax acquise localement chez des travailleurs migrants en Oman. Plasmodium vivax est le parasite du paludisme humain le plus répandu. En dehors de l'Afrique subsaharienne, la proportion de paludisme par $P$. vivax augmente. Une préoccupation majeure est la réémergence de Plasmodium vivax dans les zones sans paludisme. Oman, situé dans le coin sud-est de la péninsule arabique, est depuis longtemps une zone de transmission de $P$. vivax mais aucun cas localement acquis n'a été signalé en 2004. Cependant, la transmission locale a été rapportée dans de petites épidémies depuis 2007. Dans ce travail, une épidémie locale de 54 cas pendant 50 jours en 2014 a été analysée rétrospectivement et des lames de sang colorées ont été obtenues pour l'identification et le génotypage du parasite. L'objectif de cette étude était d'identifier l'origine géographique de ces cas, afin de différencier les cas importés et la transmission locale. Une analyse de la diversité génétique et une analyse phylogénétique ont été effectuées en utilisant les marqueurs $c s p$, mspl et msp3 pour le génotypage de l'ADN des parasites, obtenu en grattant la surface des frottis. L'étude a révélé que les échantillons avaient une très faible diversité génétique, un génotype tempéré et une grande distance génétique avec la plupart des souches de référence provenant de pays endémiques. Nous concluons qu'une petite flambée de paludisme importé n'est pas associée à la réémergence de la transmission du paludisme en Oman, car aucun nouveau cas n'a été observé après la fin de la flambée.

\footnotetext{
*Corresponding author: stephane.picot@univ-lyonl.fr
}

This is an Open Access article distributed under the terms of the Creative Commons Attribution License (http://creativecommons.org/licenses/by/4.0), which permits unrestricted use, distribution, and reproduction in any medium, provided the original work is properly cited. 


\section{Introduction}

Malaria due to $P$. vivax results in considerable morbidity and mortality $[2,6,11,16]$. P. vivax is currently the most widely distributed human malaria parasite with an estimated 2.5 billion people at risk [14]. P. vivax accounts for more than half of all malaria cases in Latin America, the Middle East, Asia, and the Western Pacific. Outside sub-Saharan Africa, the proportions of $P$. vivax malaria are rising, a clear indication of the resilience of this parasite to control measures [10, 40]. $P$. vivax has long been considered a neglected parasite while its socio-economic burden in endemic areas is huge. $P$. vivax exist in a temperate form with a long latency period up to nine months and a tropical form with a short latency period $[4,5$, $20,28,39]$. The two forms can be separated by haplotype analysis [24, 38].

The risk of introducing $P$. vivax into previously malariafree areas is related to population movements [28], as recently demonstrated in Greece $[1,8,34]$. Thus, extensive knowledge about local epidemiology and the genetics of $P$. vivax malaria is of the highest importance in order to achieve effective control measures in malaria-endemic areas.

Oman is situated in the south-eastern corner of the Arabian Peninsula, bordering the Kingdom of Saudi Arabia, the United Arab Emirates, and Yemen. The summer is hot and humid and the winter is colder with some rain. The population in 2017 was estimated to be 2.5 million Omani nationals plus an expatriate population of 2.12 million (National Centre for Statistics and Information: https:/www.ncsi.gov.om/Pages/ NCSI.aspx). Oman has long been an area of $P$. vivax malaria transmission (33,000 cases in 1990), but control aiming at eradication was started in 1991 and in 2000 the annual parasite incidence had been reduced to 1 per 10,000 population [25]. Oman registered no locally transmitted cases of malaria cases in 2004 for the first time after the eradication program started. However, in September 2007, a focus of local transmission (four cases) was found in Dakhiliya governorate and in 2008 in North Batinah governorate (eight cases). Secondary cases occurred in North Sharqiya governorate in 2010, North Sharqiya and Dakhiliya in 2011, and North and South Sharqiya and North Batinah in 2012. Local transmission was again found in 2013 in Al Dakhiliya, North, Al Batinah, and South Sharqiya governorates [25]. The number of imported cases (99.24\% of all cases) started to show a decrease from 2012 (2029 cases) to 2013 (1440 cases), while 11 locally acquired cases were detected in 2013 . These locally acquired cases most probably reflect repeated re-introduction from the high number of migrant workers from the Indian subcontinent visiting their home countries where malaria, especially $P$. vivax, is endemic.

Several molecular markers have been tested to examine parasite population diversity [7]. Microsatellites are probably the most informative markers to conduct an outbreak analysis [3, 12, 22, 23]; however, this method requires sufficient amounts of good quality DNA, and is not suitable for a retrospective analysis restricted to samples of low quality and quantity obtained after scraping of Giemsa-stained blood smears. Among the other markers generally described, genes encoding the circumsporozoite protein (csp) [17], merozoite surface protein 1 ( $m s p l)$, and merozoite surface protein 3 (msp3) have been used extensively [15, 17, 30, 32, 35]. These genetic polymorphisms have been published from samples collected in many endemic areas, leading to the possibility of investigating the origin of an outbreak by sequence comparisons. However, although a high number of sequences of these markers are available in databases, most of them have been collected in areas with high endemicity, including Brazil, India, and Papua New Guinea. Little is known about Plasmodium vivax parasites circulating in areas with low and very low endemicity or causing outbreaks in areas free of malaria.

This study is a retrospective analysis of DNA samples collected in Oman from Giemsa-stained blood films obtained from 45 patients diagnosed with malaria in 2014 and collected during a short period of less than 50 days in a focus area of $16 \mathrm{~km}^{2}$. It is important to determine whether this malaria transmission was introduced into Oman repeatedly from migrant workers coming from malaria-endemic areas, or was locally re-established.

\section{Material and methods}

\section{Ethical clearance}

This study did not impact the diagnosis, treatment, or follow-up of patients since samples were obtained after the end of the outbreak. Ethical clearance was obtained from the Ministry of Health, Sultanate of Oman.

\section{Malaria outbreak}

\section{Time of outbreak}

The first case was registered on 22 September 2014 and the last case on 9 November 2014.

\section{Geography}

All cases were found within a $4 \times 4 \mathrm{~km}$ area of Mabela, in the Seeb district of Muscat governorate, Oman. This is an area with intensive construction of new buildings.

\section{Breeding sites}

Environmental investigation was initiated and seven open water tanks related to building construction sites and 15 pools used for irrigation were sampled. Three water tanks and five pools were identified with Anopheles larvae. The malaria vector in Oman is Anopheles culicifacies.

\section{Malaria patients}

Fifty-four cases were registered from the area, 52 men and 2 women (mean age $=32 \pm 8$ ). All patients had $P$. vivax circulating blood stages as detected by experienced microscopists. One patient (Omani national) had recently traveled to Pakistan and was excluded from the study. The remaining 53 patients 
were all expatriates from India $(n=14)$, Pakistan $(n=6)$, Bangladesh $(n=32)$, and Egypt $(n=1)$. The epidemiological classification of cases was based on the field: it took into consideration the travel history of the patients, date of onset, and entomological data. From the travel history, one out of 54 patients had no travel history to a malaria-endemic country. The transmission of malaria most likely occurred near that patient.

All patients were treated with chloroquine and received a regimen of 14 days of primaquine to kill hypnozoites.

The classification of malaria cases into 1-Imported case, 2Indigenous case, 3-Introduced case, and 4-Locally acquired case, was performed according to the 2017 WHO definitions [41].

\section{DNA analysis}

Dry blood films from 45 different patients were obtained by scrapping off the surface of the smear with a scalpel and re-suspending in $100 \mu \mathrm{L}$ of phosphate-buffered saline (PBS) [33]. Genomic DNA was extracted using a QIAamp DNA mini kit (Qiagen) according to the manufacturer's instructions.

Extracted DNA was first submitted to polymerase chain reaction (PCR) for the plasmodium genus and Plasmodium vivax species detection, as previously described [26]. Considering the low amount of DNA collected from these smears, it was not possible to conduct a microsatellite analysis of parasite populations, and genotyping using nested or semi-nested PCR was performed for Pvcsp, Pvmspl (fragment 1), and Pvmsp3 alpha block II.

All amplification reactions were carried out in a total volume of $20 \mu \mathrm{L}$ and the presence of $250 \mathrm{nM}$ of each oligonucleotide primer for Pvcsp and Pvmspl or $0.1 \mu \mathrm{M}$ of each oligonucleotide primer for Pvmsp3 alpha and $2.0 \mu \mathrm{L}$ of LightCycler FastStart DNA Master SYBR Green 1 reaction mix.

Primary amplification reactions were initiated with $5.0 \mu \mathrm{L}$ of the template genomic DNA prepared from Giemsa-stained thin blood smears and $1.0 \mu \mathrm{L}$ of the product of these reactions was used to initiate the secondary amplification reactions. The cycling parameters for PCR were as follows: an initial denaturation step at $95{ }^{\circ} \mathrm{C}$ for $10 \mathrm{~min}$ preceded the cycles of annealing at a temperature defined for each primer pair for $2 \mathrm{~min}$ for Pvmsp1 and Pvcsp PCRs or $30 \mathrm{~s}$ for Pvmsp3 alpha PCR, extension step at $72{ }^{\circ} \mathrm{C}$ for 2 min for Pvmspl and Pvcsp or at $68{ }^{\circ} \mathrm{C}$ for $2.5 \mathrm{~min}$ for Pvmsp 3 alpha $\mathrm{PCR}$, and a denaturation step at $95{ }^{\circ} \mathrm{C}$ for $1 \mathrm{~min}$ for Pvmspl and Pvcsp PCRs or $30 \mathrm{~s}$ for Pvmsp3 alpha PCR.

After a final annealing step followed by 5 min of extension only for Pvmspl and Pvcsp PCRs, reaction mixtures from each capillary were collected and stored at $4{ }^{\circ} \mathrm{C}$ until secondary PCR or sequencing analysis.

The sequences were determined directly from the PCRpurified templates using a Qiagen DNA purification kit, according to the manufacturer's instructions. Direct sequencing of the full length of Pvcsp and Pvmsp3 alpha was performed in both directions using 3730 XL DNA analyzer (Applied Biosystems).

\section{Sequences analysis}

To carry out the study of the potential origin of the samples collected in Oman, nucleotide sequences with the same gene fragment were extracted from GenBank. These reference strains were selected either because they were from eight countries known to be the origin of frequent imported cases in Oman (India, Bangladesh, Pakistan, North Korea, Iran, Mauritania, Brazil, and El Salvador), or because they had the three genes available for the same strain. The accession codes and exact positions of the selected parts of the genes are reported in Table 1.

Each Omani and reference sequences were trimmed to conserve only the highest quality sequence part, using BioEdit sequence alignment editor, version 7.2.5. The alignments were done through Muscle [9] for Pvmsp1 and Pvmsp3 alpha, and had to be done manually for $\operatorname{csp}$ due to its repetitive-patterns nature. To calculate the nucleotide diversity of the genes among the Omani sequences compared to the potential diversity of the genes, Oman samples and the reference strains were analyzed using DnaSP, version 5.10.01.

These sequences have been deposited in GenBank under Submission Numbers KY629006-KY6290023 for pvcsp, KY629024-KY629045 for pvmsp1, and KY629046KY629070 for pvmsp3.

Phylogenetic inferences from concatenated amino acid sequences of Omani samples and reference strains were rooted on $P$. cynomolgi using the maximum likelihood method based on the Tamura-Nei model [36]. P. cynomolgi is the closest known relative of $P$. vivax. Initial trees for the heuristic search were obtained automatically by applying neighbor-joining and BioNJ algorithms to a matrix of pairwise distances estimated using the maximum composite likelihood (MCL) approach, and then selecting the topology with the superior log likelihood value [21].

\section{Results}

Fifty-four patients were infected during the outbreak period. The stained slides of nine patients had not been kept. Samples were collected from 45 Giemsa-stained blood smears and tested for plasmodium DNA. Three of these slides were discarded because of identification failure, DNA from five slides was degraded, and we failed to obtain DNA from two slides. Finally, DNA was obtained from 35 slides and submitted to PCR to confirm the presence of Plasmodium vivax DNA. These 35 samples were submitted to PCR for the Pvcsp, Pvmsp1, and Pvmsp 3 alpha genes, and amplicons were doublestranded sequenced. After manual cleaning of INDEL or sequencing errors, sequences from 18, 22, and 25 samples were selected for Pvcsp, Pvmsp1, and Pvmsp3 alpha, respectively (Figure 1).

The nucleotide diversity $(\pi)$ and the average number of nucleotide differences $(k)$ of Pvcsp, Pvmsp1, and Pvmsp 3 alpha were $\pi=0.00065,0.00000$, and 0.00100 and $k=0.333,0.00000$, and 0.920 , respectively. In comparison, those of the reference strains were $\pi=0.04016,0.143$, and 0.02967 and $k=9.800,39.6$, and 27.619, respectively. 
Table 1. GenBank accession numbers and selected sequence position of reference strains.

\begin{tabular}{|c|c|c|c|c|c|c|c|c|}
\hline & Brazil I & India VII & Mauritania I & North Korea & El Salvador I & Iran & Bangladesh & Pakistan \\
\hline \multirow[t]{2}{*}{$P v C S P$} & KQ234816 & KQ234274 & RC KQ235043 & KQ235379 & NC_009913 & KT588207 & & \\
\hline & $507011-507850$ & $433184-433925$ & $1478-2193$ & 59919-60852 & $1537833-1538631$ & & & \\
\hline \multirow[t]{2}{*}{$P v M S P 1$} & KQ234802 & KQ234252 & KQ235032 & KQ235335 & NC_009912 & & AF435620 & \\
\hline & $55322-55757$ & $355050-355458$ & 261679-262102 & $1203-1667$ & $1158314-1158763$ & & & \\
\hline \multirow[t]{2}{*}{$P v M S P 3 A$} & RC KQ234824 & RC KQ234312 & RC KQ235063 & RC KQ235189 & RC NC_009915 & & AF491951 & AY266090 \\
\hline & $1212661-1213729$ & $169568-170643$ & $1214086-1215161$ & $256728-257810$ & $1218991-1220078$ & & & \\
\hline
\end{tabular}

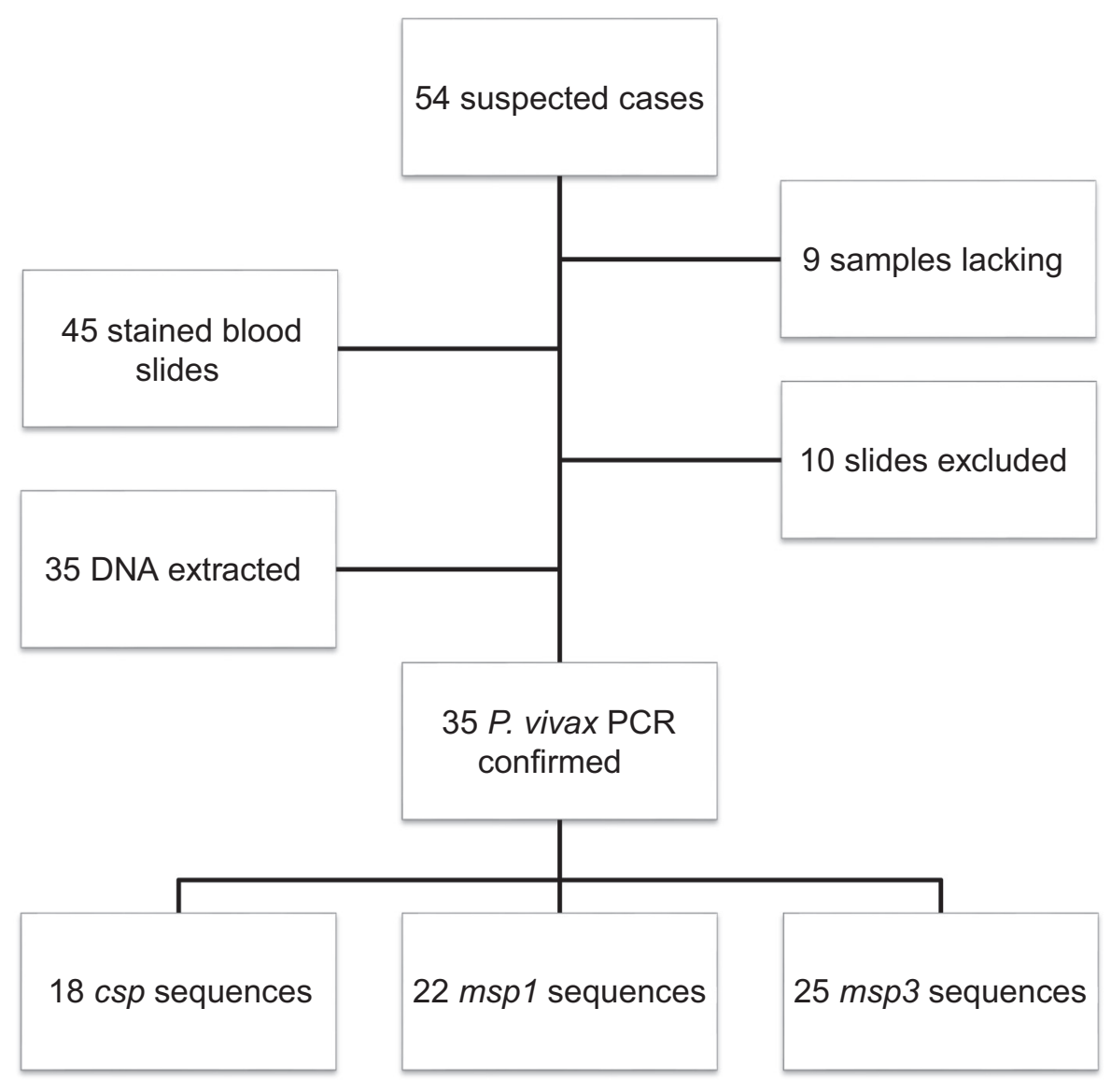

Figure 1. Study flow chart. Ten samples were excluded from the analysis due to lack of identification, DNA degradation, or absence of DNA extracted from scrapping. DNA sequences obtained after PCR for the Pvcsp, Pvmspl, and Pvmsp 3 alpha genes were cured to limit nucleotide errors, to keep sequences of the highest quality.

The circumsporozoite protein gene of $P$. vivax, located on chromosome 8 , comprises a central repetitive domain flanked by two conserved domains [17]. The repetitive domain is composed of a 27 bp element repeated a variable number of times. The VK 210 type (type I: GDRADGQPA) and the VK 247 type (type II: ANGAGNQPG) are the most useful markers for $p v c s p$ genotyping. We obtained correct $p v c s p$ sequencing for 18 samples among the 35 . All these 18 samples displayed the VK210 type with a single haplotype (six repeats of GDRADGQPA and nine repeats of GDRAAGQPA).

The merozoite surface protein 1 gene of $P$. vivax, located on chromosome 7 , encodes a protein of $190 \mathrm{kDa}$ with 7 interallele conserved blocks and 6 variable blocks. Three segments
(F1, F2, F3) have been described for $P$. vivax genotyping [31]. The F1 fragment, located at variable block 2, was sequenced here. Twenty-two samples provided good quality sequences and were further analyzed. Only one haplotype could be detected using five short tandem repeats (tripeptides) (Table 2), compared to the different haplotypes of the reference sequences from seven different areas of transmission.

The merozoite surface protein 3 alpha of $P$. vivax is a member of the msp3 family $(\alpha, \beta, \gamma)$, located on chromosome 10 , which encodes a protein with a predominant central alanine-rich domain [18]. This gene has been extensively used because of its high genetic diversity. Two blocks displayed in Pvmsp3 alpha have been studied, block I (residues 104-396) 
Table 2. Comparison of peptide repeat motifs (PRM) from seven countries to those of samples from Oman for csp, msp1, and $m s p 3$ alpha. Numbers highlighted in bold are samples with genotyping of three markers.

\begin{tabular}{|c|c|c|c|c|c|c|c|c|c|}
\hline \multirow[t]{2}{*}{ Sample ID } & \multicolumn{2}{|c|}{$c s p$} & \multicolumn{5}{|c|}{$m s p 1$} & \multicolumn{2}{|c|}{ msp3 alpha } \\
\hline & $\frac{\mathrm{VK} 210}{\mathrm{~A}}$ & $\frac{\text { VK210 }}{B}$ & SSE & SSG & SSV & GSS & GTG & KKAE & $\overline{\text { KKAK }}$ \\
\hline Brazil & 6 & 4 & 1 & 0 & 0 & 2 & 1 & 1 & 1 \\
\hline El Salvador & 10 & 6 & 1 & 0 & 0 & 3 & 1 & 1 & 1 \\
\hline Mauritania & 4 & 3 & 1 & 1 & 2 & 1 & 1 & 1 & 1 \\
\hline Iran & 7 & 8 & - & - & - & - & - & - & - \\
\hline India & 4 & 4 & 0 & 0 & 0 & 0 & 0 & 1 & 1 \\
\hline Bangladesh & - & - & 1 & 0 & 0 & 1 & 1 & 1 & 1 \\
\hline North Korea & 3 & 4 & 1 & 0 & 0 & 1 & 1 & 1 & 1 \\
\hline 2 & 6 & 10 & 1 & 1 & 2 & 1 & 1 & 1 & 1 \\
\hline 3 & & & & & & & & 1 & 1 \\
\hline 4 & & & 1 & 1 & 2 & 1 & 1 & & \\
\hline 6 & & & & & & & & 1 & 1 \\
\hline 7 & & & 1 & 1 & 2 & 1 & 1 & & \\
\hline 8 & & & 1 & 1 & 2 & 1 & 1 & 1 & 1 \\
\hline 9 & & & 1 & 1 & 2 & 1 & 1 & & \\
\hline 12 & 6 & 10 & & & & & & 1 & 1 \\
\hline 13 & & & & & & & & 1 & 1 \\
\hline 17 & & & & & & & & 1 & 1 \\
\hline 19 & & & 1 & 1 & 2 & 1 & 1 & 1 & 1 \\
\hline 21 & 6 & 10 & & & & & & 1 & 1 \\
\hline 22 & & & 1 & 1 & 2 & 1 & 1 & 1 & 1 \\
\hline 23 & & & 1 & 1 & 2 & 1 & 1 & 1 & 1 \\
\hline 24 & 6 & 10 & 1 & 1 & 2 & 1 & 1 & 1 & 1 \\
\hline 25 & & & 1 & 1 & 2 & 1 & 1 & 1 & 1 \\
\hline 26 & 6 & 10 & 1 & 1 & 2 & 1 & 1 & 1 & 1 \\
\hline 27 & & & 1 & 1 & 2 & 1 & 1 & & \\
\hline 28 & & & 1 & 1 & 2 & 1 & 1 & & \\
\hline 31 & & & 1 & 1 & 2 & 1 & 1 & & \\
\hline 32 & & & 1 & 1 & 2 & 1 & 1 & 1 & 1 \\
\hline 33 & & & 1 & 1 & 2 & 1 & 1 & & \\
\hline 34 & & & 1 & 1 & 2 & 1 & 1 & & \\
\hline 35 & & & & & & & & 1 & 1 \\
\hline 36 & & & 1 & 1 & 2 & 1 & 1 & 1 & 1 \\
\hline 37 & 6 & 10 & & & & & & 1 & 1 \\
\hline 38 & 6 & 10 & & & & & & & \\
\hline 39 & 6 & 10 & 1 & 1 & 2 & 1 & 1 & & \\
\hline 40 & 6 & 10 & & & & & & & \\
\hline 41 & & & & & & & & 1 & 1 \\
\hline 42 & 6 & 10 & 1 & 1 & 2 & 1 & 1 & 1 & 1 \\
\hline 43 & 6 & 10 & & & & & & 1 & 1 \\
\hline 45 & 6 & 10 & & & & & & 1 & 1 \\
\hline 46 & 6 & 10 & & & & & & 1 & 1 \\
\hline 47 & 6 & 10 & & & & & & 1 & 1 \\
\hline 48 & 6 & 10 & 1 & 1 & 2 & 1 & 1 & & \\
\hline 51 & 6 & 10 & & & & & & & \\
\hline 52 & 6 & 10 & & & & & & 1 & 1 \\
\hline 53 & 6 & 10 & 1 & 1 & 2 & 1 & 1 & & \\
\hline
\end{tabular}

and block II (434-687), which is known to be relatively well conserved. Its main non-random polymorphisms appear in motif I from amino acid positions 533 to 538 and in motif II from 580 to 587 [13, 27, 29]. Our analysis, focused on residues 378-688, enabled us to analyze the block II motifs. The strains from Oman, Pakistan, and El Salvador displayed the motif association MSELEK/TANVVKD, those from North Korea, Mauritania, and India displayed MSELEK/KEATAAKL, the strain from Brazil displayed LSKLEE/TAANVVKD, and the strain from Bangladesh displayed LSKLEE/KEATAAKL. While the Omani samples all displayed the same motifs, two of them had an error-like non-sense mutation. Short tandem repeats were detected in all the sequences, but the haplotypes were similar in all the Omani samples and in the reference sequences, and no information could be obtained from these sequence analyses.

Phylogenetic inference showed that Omani samples did not share a node with most of the reference strains (Figures 2-4). 


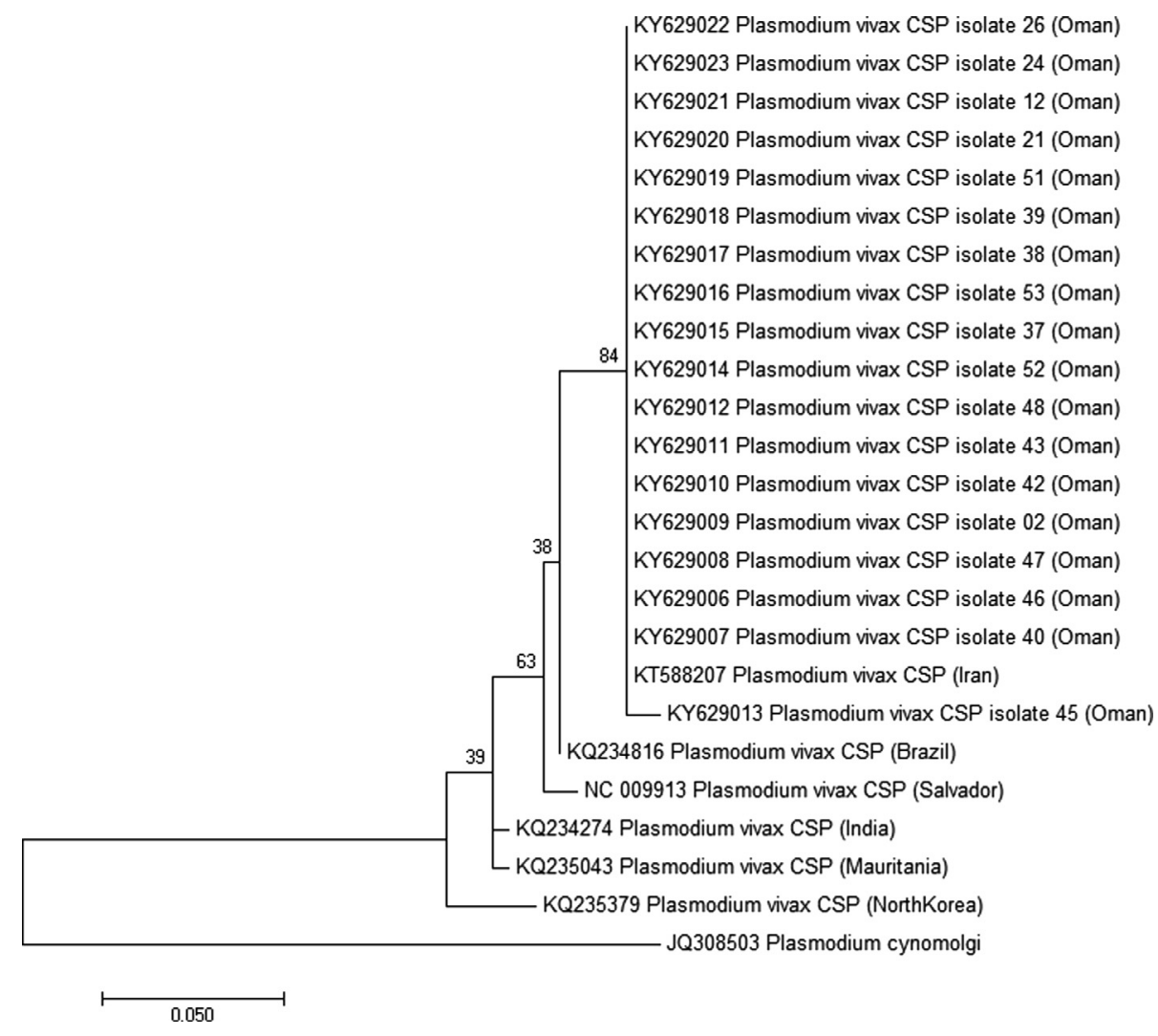

Figure 2. Molecular phylogenetic analysis by maximum likelihood method for the 18 sequences of Pvcsp protein from Oman and six reference strains. The evolutionary history was inferred by using the maximum likelihood method based on the Tamura-Nei model [36]. The tree with the highest log likelihood $(-587.1315)$ is shown. The tree is drawn to scale, with branch lengths measured in the number of substitutions per site. The analysis involved 25 nucleotide sequences. All positions containing gaps and missing data were eliminated. There were a total of 220 positions in the final dataset. Evolutionary analyses were conducted in MEGA7 [21]. The tree was rooted on Plasmodium cynomolgi csp. Bootstrap test results are shown next to the branches.

Surprisingly, samples from Oman were not closely related to samples from India, Bangladesh, or Pakistan, while most of the patients included came from these countries. Using Pvcsp, the reference sequence from Iran showed the lowest divergence with the Omani samples (Figure 2). Unfortunately, no Pvmsp 1 and Pvmsp3 alpha sequences from Iran were available from GenBank to confirm this relationship (Figures 3 and 4).

\section{Discussion}

Oman has managed to control local transmission of malaria, and for the first time no local transmission of malaria was reported in 2004. This is of the utmost importance for Oman, since potential re-introduction of the parasite would have social, economic, and tourism consequences. The Omani population is divided into Omani nationals (approx. 54\% of the population) and migrant workers (approx. $46 \%$ of the population). One of the major concerns for the Omani Health Authorities is that migrants mainly originate from countries in Southeast Asia with endemic P. vivax malaria. These immigrants work for several months on building construction sites and in agriculture, live in close proximity to water tanks, and are thus subject to mosquito bites.

An outbreak of malaria cases was detected by staff at the Department of Malaria, Ministry of Health, Oman, and stained blood smears were obtained from finger pricks and used for the diagnosis. Venous blood samples were not collected at the time of diagnosis and patients were not followed up. Thus, the only DNA material available to investigate the outbreak was the stained thick blood smears. The low quality and quantity of this material preclude a deep genetic analysis and it was not possible to use microsatellite analysis or whole-genome sequencing. DNA was obtained from 35 slides, and PCR sequencing made it possible to obtain 18,22 , and 29 sequences of the conventional markers Pvcsp, Pvmsp1, and Pvmsp3 alpha, respectively.

The measures of genetic polymorphism using nucleotide diversity $(\pi)$ and average number of nucleotide differences $(k)$ showed that all 35 samples were very closely related and thus most probably originated from a single index case. This is in agreement with the hypothesis of a series of secondary locally acquired cases contracted from a gametocyte carrier infected outside Oman. These carriers may have been in the 


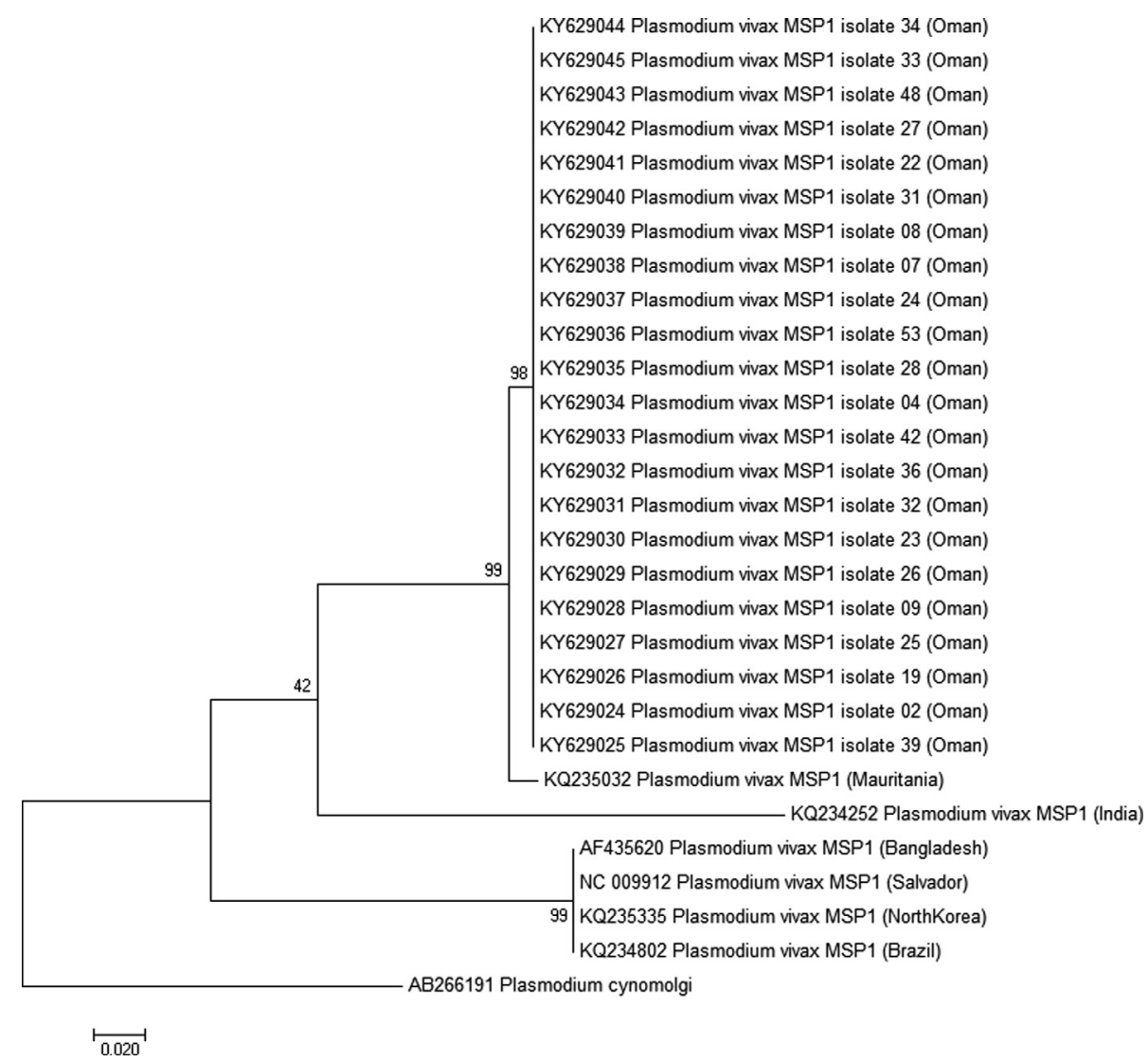

Figure 3. Molecular phylogenetic analysis by maximum likelihood method for the 22 sequences of $P v m s p 1$ protein from Oman and six reference strains. The evolutionary history was inferred by using the maximum likelihood method based on the Tamura-Nei model [36]. The tree with the highest $\log$ likelihood $(-880.6611)$ is shown. The tree is drawn to scale, with branch lengths measured in the number of substitutions per site. The analysis involved 29 nucleotide sequences. All positions containing gaps and missing data were eliminated. There were a total of 243 positions in the final dataset. Evolutionary analyses were conducted in MEGA7 [21]. The tree was rooted on Plasmodium cynomolgi msp1. Bootstrap test results are shown next to the branches.

pre-patency or patency period if recently infected, or in a longterm patency period if infected with a temperate parasite genotype.

To identify the genotype of this $P$. vivax parasite population in Oman, genotyping was done using the Pvcsp gene. All the isolates showed the VK210 pure genotype, demonstrating a temperate genotype leading to the possibility of long latency between infection and reviviscence. Thus, it could be hypothesized that the cases diagnosed during this outbreak were the primary attacks of $P$. vivax malaria transmitted from a limited number or single case of symptomatic or asymptomatic carriers previously infected in a country where temperate genotypes are circulating. It should be noted that the VK210 genotype is also predominant in countries from which many Omani migrants originated, including Pakistan, Afghanistan [42, 43], and India [19]. These results may also indicate that among the species of Anopheline vectors susceptible to transmit VK210 parasites, A. culicifacies, detected in water tanks around the cases, is most probably the vector [35].

The nearly identical Pvmsp3 alpha genotype of the Omani parasites demonstrates a common origin of the cases. In fact, other studies analyzing isolates from different regions of a country displayed more polymorphism in this gene than in the collection of Omani parasites [7, 13, 37]. Motifs I and II were the same for all the Omani parasites. Two reference strains from Pakistan and El Salvador also showed this combination, but the North Korean strain which showed the highest global phylogenetic proximity to Oman parasites had a different motif.

None of the markers used allowed us to definitively establish the origin of the outbreak. Considering that the highest diversity will be observed in an area with high transmission, it could be considered that the divergence of the parasites involved in this outbreak compared to the reference sequences from Asian countries could lead us to suspect a different origin of the parasites introduced in Oman.

The proximity of Pvcsp sequences observed in Oman with a sequence from Iran deposited in GenBank (2016) does not lead to the definitive conclusion that the Omani cases were imported from Iran. The lack of available sequences of $P v m s p 1$ and Pvmsp 3 alpha from Iran precludes more detailed analysis. Migrant workers from Iran are numerous in Oman, but most of them are not exposed to the poor environmental conditions that the freelance construction workers from the Indian subcontinent are subjected to. There were no Iranian migrant 


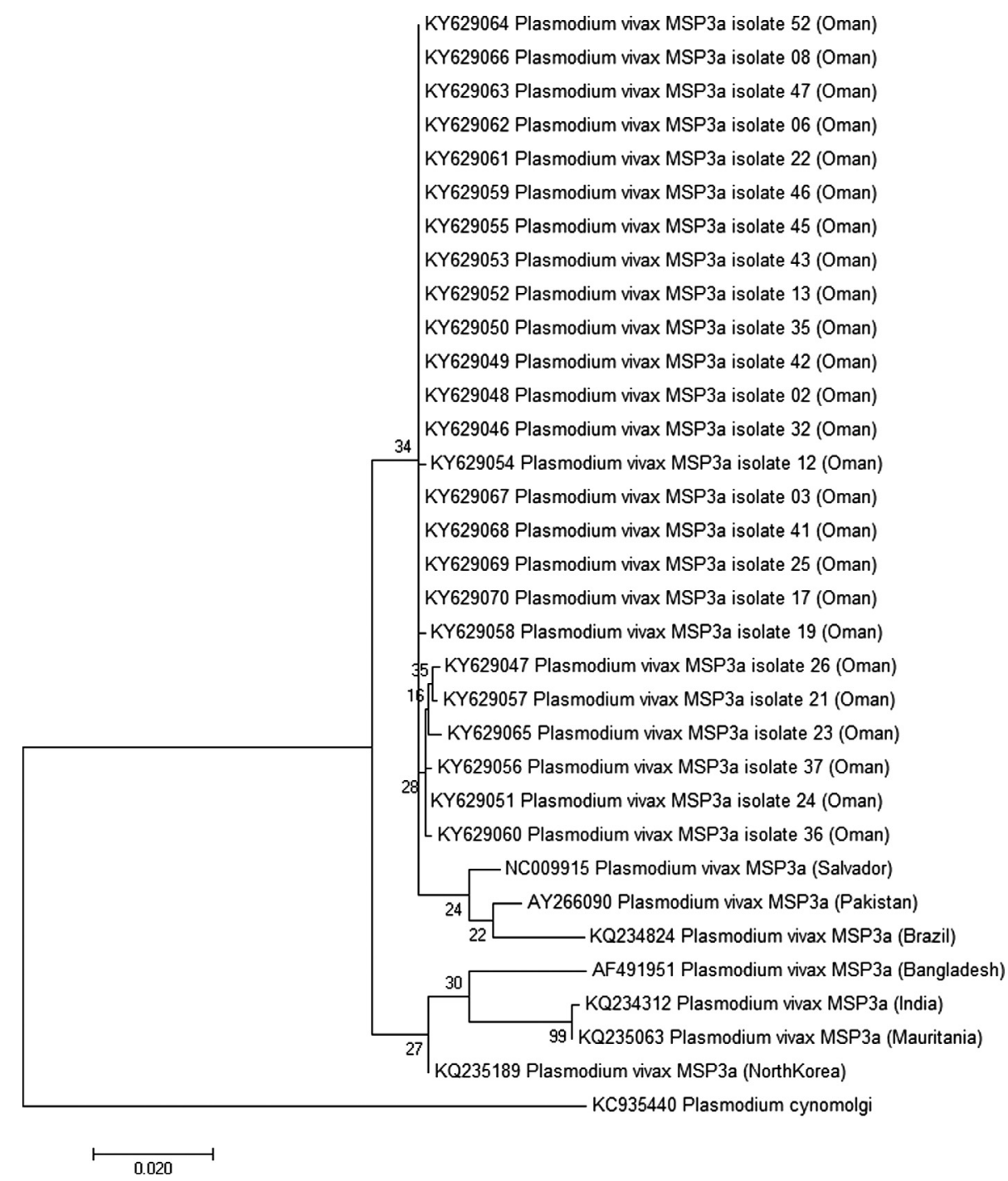

Figure 4. Molecular phylogenetic analysis by maximum likelihood method for the 25 sequences of Pvmsp 3 alpha protein from Oman and seven reference strains. The evolutionary history was inferred by using the maximum likelihood method based on the Tamura-Nei model [36]. The tree with the highest log likelihood (-2208.3432) is shown. The tree is drawn to scale, with branch lengths measured in the number of substitutions per site. The analysis involved 33 nucleotide sequences. All positions containing gaps and missing data were eliminated. There were a total of 895 positions in the final dataset. Evolutionary analyses were conducted in MEGA7 [21]. The tree was rooted on Plasmodium cynomolgi msp3a. Bootstrap test results are shown next to the branches.

workers in the area where the malaria outbreak occurred. Samples collected from Iran should be compared to Omani sequences to confirm this hypothesis.

Alternatively, the hypothesis of an Omani $P$. vivax circulating in the country and causing small outbreaks like this one is highly unlikely, given that no new cases have been seen since the outbreak ended.

\section{Conflict of interest}

The Associate Editor of Parasite, Stéphane Picot, is one of the authors of this manuscript. COPE (Committee on Publication Ethics, http://publicationethics.org), to which Parasite adheres, advises special treatment in these cases. In this case, the peer-review process was handled by the Editor-in-Chief.
Acknowledgements. This work was supported by a grant from the European Society of Clinical Microbiology and Infectious Diseases (ESCMID) ESCMID Study Group \# 9982.

\section{References}

1. Andriopoulos P, Economopoulou A, Spanakos G, Assimakopoulos G. 2013. A local outbreak of autochthonous Plasmodium vivax malaria in Laconia, Greece-a re-emerging infection in the southern borders of Europe? International Journal of Infectious Diseases, 17, e125-e128.

2. Anvikar AR, Shah N, Dhariwal AC, Sonal GS, Pradhan MM, Ghosh SK, Valecha N. 2016. Epidemiology of Plasmodium vivax malaria in India. The American Journal of Tropical Medicine and Hygiene, 95(6 Suppl), 108-120. 
3. Batista CL, Barbosa S, Da Silva Bastos M, Viana SAS, Ferreira MU. 2015. Genetic diversity of Plasmodium vivax over time and space: a community-based study in rural Amazonia. Parasitology, 142, 374-384.

4. Battle KE, Karhunen MS, Bhatt S, Gething PW, Howes RE, Golding N, Van Boeckel TP, Messina JP, Shanks GD, Smith DL, Baird JK, Hay SI. 2014. Geographical variation in Plasmodium vivax relapse. Malaria Journal, 13, 144.

5. Bray RS, Garnham PC. 1982. The life-cycle of primate malaria parasites. British Medical Bulletin, 38(2), 117-122.

6. Chery L, Maki JN, Mascarenhas A, Walke JT, Gawas P, Almeida A, Fernandes M, Vaz M, Ramanan R, Shirodkar D, Bernabeu M, Manoharan SK, Pereira L, Dash R, Sharma A, Shaik RB, Chakrabarti R, Babar P, White J 3rd, Mudeppa DG, Kumar S, Zuo W, Skillman KM, Kanjee U, Lim C, Shaw-Saliba K, Kumar A, Valecha N, Jindal VN, Khandeparkar A, Naik P, Amonkar S, Duraisingh MT, Tuljapurkar S, Smith JD, Dubhashi N, Pinto RG, Silveria M, Gomes E, Rathod PK. 2016. Demographic and clinical profiles of Plasmodium falciparum and Plasmodium vivax patients at a tertiary care centre in southwestern India. Malaria Journal, 15(1), 569.

7. Cui L, Mascorro CN, Fan Q, Rzomp KA, Khuntirat B, Zhou G, Chen H, Yan G, Sattabongkot J. 2003. Genetic diversity and multiple infections of Plasmodium vivax malaria in Western Thailand. The American Journal of Tropical Medicine and Hygiene, 68, 613-619.

8. Dimopoulou D, Piperaki ET, Zerva L, Tsagris V, Asprogeraka S, Kalantzis D, Papaevangelou V. 2017. Concurrent autochthonous malaria caused by Plasmodium vivax in father and son in Greece. Journal of Tropical Pediatrics, 63, 74-77.

9. Edgar RC. 2004. MUSCLE: a multiple sequence alignment method with reduced time and space complexity. BMC Bioinformatics, 5, 113.

10. Ferreira MU, Castro MC. 2016. Challenges for malaria elimination in Brazil. Malaria Journal, 15, 284.

11. Galinski MR, Barnwell JW. 2008. Plasmodium vivax: who cares? Malaria Journal, 7(Suppl 1), S9.

12. Gunawardena S, Karunaweera ND, Ferreira MU, Phone-Kyaw M, Pollack RJ, Alifrangis M, Rajakaruna RS, Konradsen F, Amerasinghe PH, Schousboe ML, Galappaththy GN, Abeyasinghe RR, Hartl DL, Wirth DF. 2010. Geographic structure of Plasmodium vivax: microsatellite analysis of parasite populations from Sri Lanka, Myanmar, and Ethiopia. The American Journal of Tropical Medicine and Hygiene, 82, 235-242.

13. Gupta B, Reddy BPN, Fan Q, Yan G, Sirichaisinthop J, Sattabongkot J, Escalante AA, Cui L. 2015. Molecular evolution of PvMSP $3 \alpha$ block II in Plasmodium vivax from diverse geographic origins. PLoS One, 10, e0135396.

14. Howes RE, Battle KE, Mendis KN, Smith DL, Cibulskis RE, Baird JK, Hay SI. 2016. Global epidemiology of Plasmodium vivax. The American Journal of Tropical Medicine and Hygiene, 95, 15-34.

15. Huang B, Huang S, Su X, Guo H, Xu Y, Xu F, Hu X, Yang Y, Wang S, Lu F. 2014. Genetic diversity of Plasmodium vivax population in Anhui province of China. Malaria Journal, $13,13$.

16. Im JH, Kwon HY, Baek J, Park SW, Durey A, Lee KH, Chung MH, Lee JS. 2017. Severe Plasmodium vivax infection in Korea. Malaria Journal, 16(1), 51.
17. Imwong $\mathrm{M}$, Pukrittayakamee $\mathrm{S}$, Grüner $\mathrm{AC}$, Rénia $\mathrm{L}$, Letourneur F, Looareesuwan S, White NJ, Snounou G. 2005. Practical PCR genotyping protocols for Plasmodium vivax using Pvcs and Pvmsp1. Malaria Journal, 4, 20.

18. Jiang J, Barnwell JW, Meyer EVS, Galinski MR. 2013. Plasmodium vivax merozoite surface protein-3 (PvMSP3): expression of an 11 member multigene family in blood-stage parasites. PLoS One, 8, e63888.

19. Kim J-R, Imwong M, Nandy A, Chotivanich K, Nontprasert A, Tonomsing N, Maji A, Addy M, Day NPJ, White NJ, Pukrittayakamee S. 2006. Genetic diversity of Plasmodium vivax in Kolkata, India. Malaria Journal, 5, 71.

20. Kim J-R, Nandy A, Maji AK, Addy M, Dondorp AM, Day NPJ, Pukrittayakamee S, White NJ, Imwong M. 2012. Genotyping of Plasmodium vivax reveals both short and long latency relapse patterns in Kolkata. PLoS One, 7, e39645.

21. Kumar S, Stecher G, Tamura K. 2016. MEGA7: Molecular Evolutionary Genetics Analysis version 7.0 for bigger datasets. Molecular Biology and Evolution, 33, 1870-1874.

22. Menegon M, Durand P, Menard D, Legrand E, Picot S, Nour B, Davidyants V, Santi F, Severini C. 2014. Genetic diversity and population structure of Plasmodium vivax isolates from Sudan, Madagascar, French Guiana and Armenia. Infection Genetics and Evolution, 27, 244-249.

23. Menegon M, Bardají A, Martínez-Espinosa F, Bôtto-Menezes C, Ome-Kaius M, Mueller I, Betuela I, Arévalo-Herrera M, Kochar S, Kochar SK, Jaju P, Hans D, Chitnis C, Padilla N, Castellanos ME, Ortiz L, Sanz S, Piqueras M, Desai M, Mayor A, Del Portillo H, Menéndez C, Severini C. 2016. Microsatellite genotyping of Plasmodium vivax isolates from pregnant women in four malaria endemic countries. PLoS One, 11, e0152447.

24. Miao M, Yang Z, Patch H, Huang Y, Escalante AA, Cui L. 2012. Plasmodium vivax populations revisited: mitochondrial genomes of temperate strains in Asia suggest ancient population expansion. BMC Evolutionary Biology, 17(12), 22.

25. Ministry of Health, Oman. Annual Statistical Report 2015, www.moh.gov.om.

26. de Monbrison F, Angei C, Staal A, Kaiser K, Picot S. 2003. Simultaneous identification of the four human Plasmodium species and quantification of Plasmodium DNA load in human blood by real-time polymerase chain reaction. Transactions of the Royal Society of Tropical Medicine and Hygiene, 97, 387-390.

27. Ord R, Polley S, Tami A, Sutherland CJ. 2005. High sequence diversity and evidence of balancing selection in the Pvmsp3alpha gene of Plasmodium vivax in the Venezuelan Amazon. Molecular Biochemical Parasitology, 144, 86-93.

28. Petersen E, Severini C, Picot S. 2013. Plasmodium vivax malaria: a re-emerging threat for temperate climate zones? Travel Medicine and Infectious Diseases, 11, 51-59.

29. Rayner JC, Corredor V, Feldman D, Ingravallo P, Iderabdullah F, Galinski MR, Barnwell JW. 2002. Extensive polymorphism in the Plasmodium vivax merozoite surface coat protein MSP3alpha is limited to specific domains. Parasitology, 125, 393-405.

30. Shabani SH, Zakeri S, Mehrizi AA, Mortazavi Y, Djadid ND. 2016. Population genetics structure of Plasmodium vivax circumsporozoite protein during the elimination process in low and unstable malaria transmission areas, southeast of Iran. Acta Tropica, 160, 23-34. 
31. Soares LA, Evangelista J, Orlandi PP, Almeida ME, de Sousa LP, Chaves Y, Barbosa-Filho R, Lacerda MV, Mariuba LA, Nogueira PA. 2014. Genetic diversity of MSP1 Block 2 of Plasmodium vivax isolates from Manaus (central Brazilian Amazon). Journal of Immunology Research, 2014, 671050.

32. de Souza AM, de Araújo FCF, Fontes CJF, Carvalho LH, de Brito CFA, de Sousa TN. 2015. Multiple-clone infections of Plasmodium vivax: definition of a panel of markers for molecular epidemiology. Malaria Journal, 14, 330.

33. Sow F, Bonnot G, Ahmed BR, Diagana SM, Kebe H, Koita M, Samba BM, Al-Mukhaini SK, Al-Zadjali M, Al-Abri SS, Ali OA, Samy AM, Hamid MM, Ali Albsheer MM, Simon B, Bienvenu AL, Petersen E, Picot S. 2017. Genetic diversity of Plasmodium vivax metacaspase 1 and Plasmodium vivax multidrug resistance 1 genes of field isolates from Mauritania, Sudan and Oman. Malaria Journal, 16, 61.

34. Spanakos G, Alifrangis M, Schousboe ML, Patsoula E, Tegos N, Hansson HH, Bygbjerg IC, Vakalis NC, Tseroni M, Kremastinou J, Hadjichristodoulou C. 2013. Genotyping Plasmodium vivax isolates from the 2011 outbreak in Greece. Malaria Journal, 12, 463.

35. Talha AA, Pirahmadi S, Mehrizi AA, Djadid ND, Nour BYM, Zakeri S. 2015. Molecular genetic analysis of Plasmodium vivax isolates from Eastern and Central Sudan using pvcsp and pvmsp-3 $\alpha$ genes as molecular markers. Infection Genetics and Evolution, 32, 12-22.
36. Tamura K, Nei M. 1993. Estimation of the number of nucleotide substitutions in the control region of mitochondrial DNA in humans and chimpanzees. Molecular Biology and Evolution, 10, 512-526.

37. Verma A, Joshi H, Singh V, Anvikar A, Valecha N. 2016. Plasmodium vivax msp-3 $\alpha$ polymorphisms: analysis in the Indian subcontinent. Malaria Journal, 15, 492.

38. White NJ. 2011. Determinants of relapse periodicity in Plasmodium vivax malaria. Malaria Journal, 10, 297.

39. White NJ, Imwong M. 2012. Relapse. Advances in Parasitology, 80, 113-150.

40. White MT, Yeung S, Patouillard E, Cibulskis R. 2016. Costs and cost-effectiveness of Plasmodium vivax control. The American Journal of Tropical Medicine and Hygiene, 95, 52-61.

41. World Health Organization. 2017. A framework for malaria elimination, http://www.who.int/malaria/publications/atoz/ 9789241511988/en/.

42. Zakeri S, Raeisi A, Afsharpad M, Kakar Q, Ghasemi F, Atta H, Zamani G, Memon MS, Salehi M, Djadid ND. 2010. Molecular characterization of Plasmodium vivax clinical isolates in Pakistan and Iran using pvmsp-1, pvmsp-3alpha and pvcsp genes as molecular markers. Parasitology International, 59, 15-21.

43. Zakeri S, Safi N, Afsharpad M, Butt W, Ghasemi F, Mehrizi AA, Atta H, Zamani G, Djadid ND. 2010. Genetic structure of Plasmodium vivax isolates from two malaria endemic areas in Afghanistan. Acta Tropica, 113, 12-19.

Cite this article as: Simon B, Sow F, Al Mukhaini SK, Al-Abri S, Ali OAM, Bonnot G, Bienvenu A-L, Petersen E \& Picot S: An outbreak of locally acquired Plasmodium vivax malaria among migrant workers in Oman. Parasite, 2017, $24,25$.

๑) PARASTE

An international open-access, peer-reviewed, online journal publishing high quality papers on all aspects of human and animal parasitology

Reviews, articles and short notes may be submitted. Fields include, but are not limited to: general, medical and veterinary parasitology; morphology, including ultrastructure; parasite systematics, including entomology, acarology, helminthology and protistology, and molecular analyses; molecular biology and biochemistry; immunology of parasitic diseases; host-parasite relationships; ecology and life history of parasites; epidemiology; therapeutics; new diagnostic tools.

All papers in Parasite are published in English. Manuscripts should have a broad interest and must not have been published or submitted elsewhere. No limit is imposed on the length of manuscripts.

Parasite (open-access) continues Parasite (print and online editions, 1994-2012) and Annales de Parasitologie Humaine et Comparée (1923-1993) and is the official journal of the Société Française de Parasitologie.
Submit your manuscript at http://parasite.edmgr.com/ 